\title{
Duodenal Papilla
}

National Cancer Institute

\section{Source}

National Cancer Institute. Duodenal Papilla. NCI Thesaurus. Code C119578.

Either one of two openings from the pancreatic ducts into the duodenum. The major duodenal papilla opens from the pancreatic duct into the duodenum. The minor duodenal papilla opens from the accessory pancreatic duct into the descending second section of the duodenum. 